\title{
Effects of cooking on antinutrients and antioxidant properties of different accessions of winged bean (Psophocarpus tetragonolobus)
}

\author{
1, ${ }^{*}$ Maimako, R.F., ${ }^{1}$ Awakan, O.J., ${ }^{2}$ Olaniran, A.F., ${ }^{2}$ Olasunkanmi, O.P. and ${ }^{1}$ Oluba, O.M. \\ ${ }^{1}$ Department of Biochemistry, Landmark University, Km 4, Ipetu Road, Omu Aran, 251101, Kwara State, \\ Nigeria \\ ${ }^{2}$ Department of Agricultural Sciences, Landmark University, Km 4, Ipetu Road, Omu Aran, 251101, Kwara \\ State, Nigeria
}

\section{Article history: \\ October 2020 \\ 2022 \\ Keywords: \\ Antioxidant, \\ Antinutrient, \\ Winged bean, \\ Food processing, \\ Legumes, \\ Functional food}

Received: 22 September 2020

Received in revised form: 28

Accepted: 1 January 2021

Available Online: 9 February

\section{DOI:}

https://doi.org/10.26656/fr.2017.6(1).527

\begin{abstract}
Asides from its robust nutritional profile, Psophocarpus tetragonolobus also possesses other health-promoting attributes. Hence, this study was designed to investigate the antinutrient content and antioxidant property of five different varieties of raw and cooked $P$. tetragonolobus. The varieties studied included, the indigenous variety (designated local) and four improved varieties (designated: T11, T31, T125, T154). Antinutrients like phenolic, tannin, glycoside and phytate concentrations were determined using standard methods while 2,2-diphenyl-1-picrylhydrazyl (DPPH) assay was carried out to ascertain the antioxidant activity. Phytate, cyanogenic glycosides and tannin levels were significantly $(\mathrm{p}<0.05)$ reduced due to cooking in T11 variety. In T125 variety, tannin was significantly lower in the cooked sample compared to the raw sample. However, the phenolic content in the T125 variety increased significantly $(\mathrm{p}<0.05)$ due to cooking. There was no significant difference in antioxidant activity between the raw and cooked samples across the five varieties. However, the improved varieties showed higher antioxidant activity compared to the local. Based on these results, the cooking process reduced the phytate, cyanogenic glycosides and tannin levels in the T11 variety while only the tannin level in T125 variety was significantly reduced. However, the antioxidant activity of $P$. tetragonolobus was not significantly impacted by cooking.
\end{abstract}

\section{Introduction}

All groups of people are affected by malnutrition but those most prone are pregnant women, infants, and children. Several policies are being implemented globally towards combatting malnutrition, especially in third world countries. And up to date, it remains a challenge to policymakers and scientists globally. Despite the worldwide problem of malnutrition, out of the 1000 legumes grown on a global scale, only about 20 are studied and utilized for food and health purposes (Kumar and Pandey, 2020). This means a larger percentage of these legumes are under-utilized, understudied and underexploited.

Underutilization and neglect are some of the underlying challenges in the utilization of legumes in human nutrition, especially in underdeveloped countries that have a higher incidence of malnutrition in children and pregnant women. Underutilization can be because of the hard to cook nature of some of these legumes and also little information on potential food and health benefits of such underutilised legumes (Subuola et al., 2012). A number of these underutilized legumes are grown in the subtropics, tropics, and also temperate regions and they possess distinct genetic traits. They are reported to convey several health advantages. A lot of the underutilized varieties of legumes contain many nutrients, anti-nutrients, and bioactive components (Diniyah et al., 2020).

The main nutritional component in legume structure is the cotyledon which has been reported to be rich in proteins and starch. Heating thus alters the structure of the cotyledon. Heating has been observed to cause losses of both antinutrients and nutrients, which could be either through thermal degradation or diffusion (Coffigniez et al., 2019). Legumes have for long been associated with reduced chronic disease conditions which emphasize their dietary importance in the world's population today (Diniyah et al., 2020). It is reported that the risk factor of over ten significant chronic diseases is reduced by the 
consumption of legume. These functions can be due to the presence of various antinutrients found in legumes (Aranda-Olmedo and Rubio, 2020).

Winged bean (Psophocarpus tetragonolobus) is an unconventional crop of the legume family although having related nutritional composition with soybean it is underexploited (Chen et al., 2015; Makeri et al., 2019). It belongs to the family Fabaceae (Leguminosae) and is commonly known as the winged bean, Goa bean, Asparagus pea or wonder legume (Lepcha et al., 2017; Singh et al., 2019). It is usually grown for various purposes, as a vegetable, grain legume, tuber, forage, or cover crop (Mohanty et al., 2015). It is said to have a greater yield and more soil enriching properties than many other legumes (Lepcha et al., 2017).

\section{P. tetragonolobus contains important} pharmacological anti-nutrients such as haematoglutins and amylase inhibitors, chymotrypsin and trypsin inhibitors (Mohanty et al., 2013). Much attention is now given to this plant because of its rich protein content and versatility. All the plant parts (pod, leaves, flowers, and even the tubers) without exception are edible thus the plant is called "one stalk supermarket," or "God-given plant” (Mohanty et al., 2013; Singh et al., 2019). Though, limited scientific information on the antioxidant and anti-nutrient content of the processed and unprocessed $P$. tetragonolobus has been documented.

In this study, we examined the effects of cooking on the antinutrients and antioxidant potentials of five different accessions of winged bean.

\section{Materials and methods}

\subsection{Plant materials}

Five distinct varieties of matured dried seeds of $P$. tetragonolobus consisting of one indigenous (designated as local) and four improved varieties (designated: Tpt11, Tpt-31, Tpt-125, and Tpt-154) were obtained from the College of Agricultural Sciences, Landmark University, Omu-Aran (Nigeria). The seeds were sorted by handpicking and then divided into two equal portions. The first portion was left uncooked (raw) while the second portion was cooked (as described under the cooking process).

\subsubsection{Raw sample}

Dried raw seeds of $P$. tetragonolobus were ground to powder using a mechanical grinder, sieved with a 0.5 $\mathrm{mm}$ sieve and then kept in an airtight container at $4^{\circ} \mathrm{C}$ until required for analysis.

\subsubsection{Cooking process}

A total of $100 \mathrm{~g}$ of winged bean was measured and poured into $1 \mathrm{~L}$ of boiling water on a hot plate. The winged bean was allowed to cook at $300^{\circ} \mathrm{C}$ using a hot plate for $4 \mathrm{hrs}$ till it was soft to the touch and the water completely evaporated. It was then allowed to cool in a tray and transferred to an oven for drying at $50^{\circ} \mathrm{C}$. The dried cooked sample was ground in a mechanical grinder, sieved with a $0.5 \mathrm{~mm}$ sieve and then kept in an airtight container at $4^{\circ} \mathrm{C}$ until required for analysis (Teixeira-Guedes et al., 2019).

Samples of the five varieties raw and cooked were represented thus;

Local Raw (LR); Local Cooked (LC); Tpt-11 Raw (T11R); Tpt-11 Cooked (T11C); Tpt-31 Raw (T31R); Tpt-31 Cooked (T31C); Tpt-125 Raw (T125R); Tpt-125 Cooked (T125C); Tpt-154 Raw (T154R) and Tpt-154 Cooked (T154C).

\subsection{Determining antinutritional factors}

\subsubsection{Phytate analyses}

Protein powder $(2 \mathrm{~g})$ was dispersed in $50 \mathrm{~mL}$ of $\mathrm{HCl}$ (2\%) and shaken on an orbital shaker for $3 \mathrm{hrs}$. It was then filtered using Whatman filter paper no. 1 and mixed with $2.5 \mathrm{~mL}$ of $\mathrm{NH}_{4} \mathrm{SCN}(0.3 \%)$ and $27 \mathrm{~mL}$ of distilled water. This was titrated against $\mathrm{FeCl}_{3}(1.95 \mathrm{mg} / \mathrm{mL})$ until a brownish yellow colour persisted. The phytate concentration was determined considering the molecule is $28.2 \%$ phosphorus using the equation (Kumar and Pandey, 2020):

Phytate phosphorus $[\mathrm{mg} / 100 \mathrm{~g}$ (d. w.) $]=$ Iron equivalent (titre value) $\times 1.95$

Phytate $[\mathrm{mg} / 100 \mathrm{~g}$ (d.w.) $]=$ Phytate phosphorus $\times 3.55$

\subsubsection{Cyanogenic glycosides}

The dried seed was weighed $(5 \mathrm{~g})$ and suspended in distilled water in a conical flask, it was then left to stay overnight. The solution was filtered, and $2 \mathrm{~mL}$ of the filtrate was transferred into a conical flask. Then, $4 \mathrm{~mL}$ of alkaline picrate solution was added to the solution and incubated in a water bath at $70^{\circ} \mathrm{C}$ for 5 mins, for the colour development (reddish-brown) and the absorbance was read by a UV Vis spectrophotometer at $490 \mathrm{~nm}$. Also, a blank was prepared using $2 \mathrm{~mL}$ of the distilled water. The cyanide content was extrapolated from a cyanide standard curve. Sodium cyanide was used as the standard for the standard curve preparation. A stock solution of $2 \mathrm{mg} / \mathrm{mL}$ concentration of sodium cyanide was used in the preparation of serial dilution of cyanide from $25-225 \mu \mathrm{l} / \mathrm{mL}$ range (Owuamanam et al., 2014). 


\subsubsection{Total phenolic content}

Total phenolic content was determined using FolinCiocalteu's reagent. An aliquot of $100 \mu \mathrm{L}$ of diluted sample was mixed with $625 \mu \mathrm{L}$ of distilled water, $250 \mu \mathrm{L}$ of $7.5 \%(\mathrm{w} / \mathrm{v})$ sodium carbonate and $25 \mu \mathrm{L}$ of $2 \mathrm{~N}$ FolinCiocalteu's phenol reagent. The reaction mixture was then left to incubate at room temperature for $2 \mathrm{hrs}$ in the dark. The absorbance was read at $739 \mathrm{~nm}$ with a UV/Vis spectrophotometer. A gallic acid standard curve with a linear range $(0-225 \mu \mathrm{g} / \mathrm{mL})$ was prepared from a freshly made $1 \mathrm{mg} / \mathrm{mL}$ stock solution. Results were expressed as $\mathrm{mg}$ of gallic acid equivalents (GAE)/g of soluble fraction (Bautista-Exposito et al., 2018).

\subsubsection{Total tannin}

About $0.5 \mathrm{~g}$ of sample was measured and transferred to a $50 \mathrm{~mL}$ conical flask followed by the addition of 25 $\mathrm{mL}$ of distilled water. The solution was boiled for about 30 mins followed by centrifugation for $20 \mathrm{~min}$ at 5000 $\mathrm{rpm}$. The supernatant was separated and $0.1 \mathrm{~mL}$ of it was taken into a test tube with the addition of $0.5 \mathrm{~mL}$ of Folin -Ciocalteu reagent $1 \mathrm{~N}, 1 \mathrm{~mL}$ of sodium carbonate $(20 \%)$ was added to it. The final volume of the tube was made up of distilled water to $10 \mathrm{~mL}$. The solution was incubated at room temperature $30 \mathrm{~min}$ and the absorbance was read using a UV/Vis spectrophotometer at $700 \mathrm{~nm}$ and the tannin content was expressed as $\mathrm{mg} / \mathrm{g}$ (Mohapatra et al., 2019).

$$
1 \mathrm{~N}=2 \mathrm{~N}(\text { as supplied })+\text { equal volume of water }
$$

Standard tannic solution $(0.5 \mathrm{mg} / \mathrm{mL})$ was freshly prepared.

\subsection{DPPH scavenging activity}

The protein sample ( $2 \mathrm{~g}$ ) was weighed and dispersed into $25 \mathrm{~mL}$ of $70 \%$ ethanol. The solution was extracted overnight in the dark at room temperature. To $0.1 \mathrm{~mL}$ of the extract, $3.9 \mathrm{~mL}$ of DPPH solution $(80 \mu \mathrm{g} /$ ethanol $)$ was added, and the blank was made by adding $0.1 \mathrm{~mL}$ distilled water with $3.9 \mathrm{~mL}$ DPPH solution. The sample was kept in the dark at room temperature for 30 mins. Absorbance was read at $517 \mathrm{~nm}$ using a UV/Vis spectrophotometer. The percentage inhibition of DPPH was ascertained using the following expression (Mohapatra et al., 2019).

$\%$ inhibition of DPPH $=\frac{\text { Absorbance(blank) }- \text { Absorbance }(\text { sample })}{\text { Absorbance }(\text { blank) }} \times 100$

Where $\mathrm{A}($ blank $)=$ absorbance of blank at $\mathrm{t}=0$ and $\mathrm{A}($ sample $)=$ absorbance of sample at $\mathrm{t}=30 \mathrm{mins}$

The analysis was carried out in triplicate and the average value reported.

\subsection{Data analysis}

All analysis was performed in triplicate and expressed as mean \pm SD. Data analysis was performed using analysis of variance (ANOVA) with GraphPad prism. The significant level was set at $P<0.05$.

\section{Results}

\subsection{Phytate}

The phytate concentration of all the improved varieties was higher than the local variety as shown in Figure 1. The phytate concentration of T11 variety showed a significant reduction $(p<0.05)$ on cooking, though phytate concentration of T31 and T125 reduced due to cooking, the decrease was however not significant $(p>0.05)$. T11 variety raw showed the highest phytate concentration of $8.77 \mathrm{mg} / 100 \mathrm{~g}$ while local raw and local cooked varieties showed the lowest phytate concentration at $3.00 \mathrm{mg} / 100 \mathrm{~g}$.

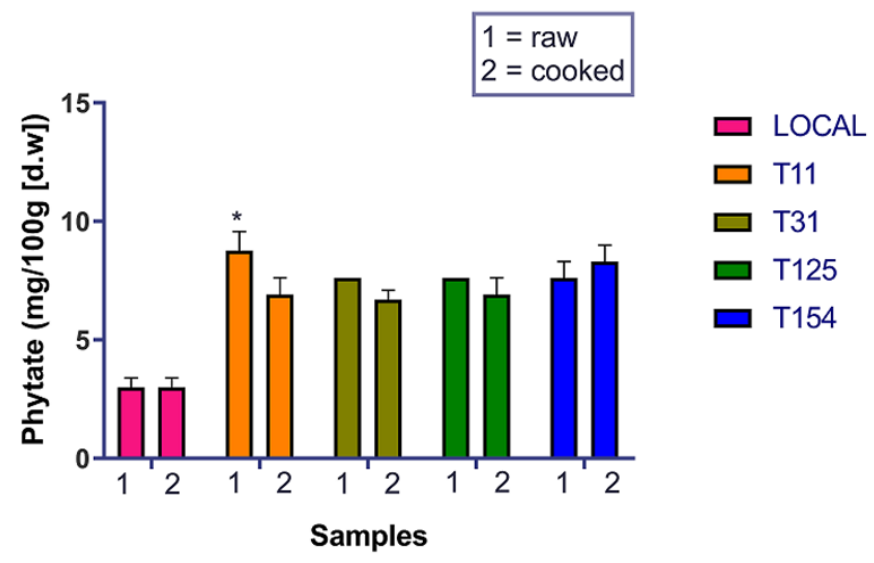

Figure 1. Effect of cooking on phytate concentration in five different varieties of $P$. tetragonolobus. LOCAL - indigenous variety, T11, T31, T125, T154 -Tpt-11, Tpt-31, Tpt-125, Tpt154 (improved variety), 1 - raw, 2 - cooked, * - significant difference.

\subsection{Cyanogenic glycoside}

From Figure 2, cooking had a significant effect $(p<0.05)$ on three of the samples as local raw and T125 raw varieties significantly increased $(p<0.05)$ on cooking while T11 raw significantly decreased $(p<0.05)$ on cooking. The highest mean value of glycoside concentration was observed in the local variety cooked sample $(462.80 \mathrm{mg} / \mathrm{mL})$ while the lowest was observed in the local variety raw $(170.50 \mathrm{mg} / \mathrm{mL})$.

\subsection{Phenolic}

Phenolic content was not detected in local variety raw while the lowest concentration was seen in local variety cooked as $28.63 \mathrm{mg} / \mathrm{g}$. T11 variety cooked showed the highest phenol concentration of $402.90 \mathrm{mg} /$ 


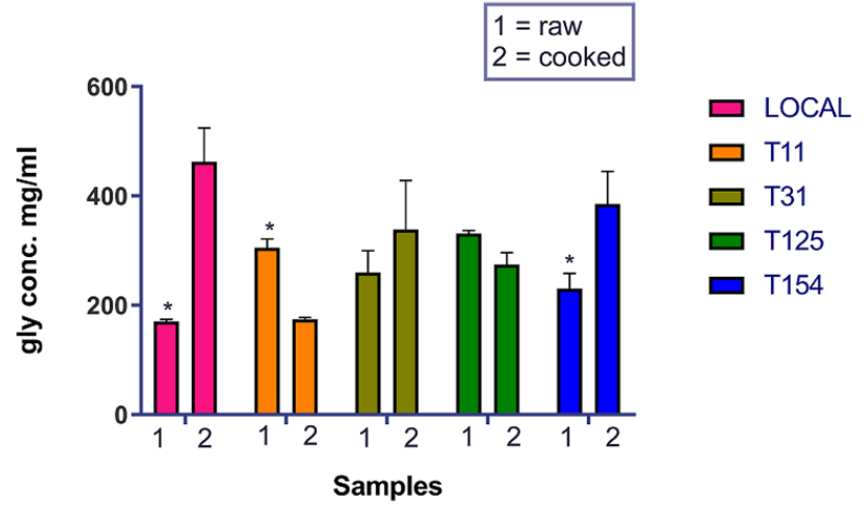

Figure 2. Effect of cooking on cyanogenic glycoside content in five different varieties of $P$. tetragonolobus. LOCAL indigenous variety, T11, T31, T125, T154 -Tpt-11, Tpt-31, Tpt-125, Tpt-154 (improved variety), 1 - raw, 2 - cooked, * significant difference.

$\mathrm{mL}$. There was a significant increase $(p<0.05)$ in T154 variety after cooking. Thus, the improved variety showed higher phenolic concentration than the local variety from Figure 3.

\subsection{Tannin}

The tannin concentration of the improved variety of $P$. tetragonolobus was higher than that of the local counterpart from Figure 4. T154 variety cooked had the highest tannin content of $402.10 \mu \mathrm{g} / \mathrm{mL}$ while local variety raw had the lowest tannin concentration of 92.75 $\mu \mathrm{g} / \mathrm{mL}$. T11 and T125 varieties showed a significant decrease $(p<0.05)$ in tannin content due to cooking.

\subsection{DPPH activity}

DPPH scavenging activity of all the samples depicted in Figure 5 did not show a significant effect $(p>0.05)$ on cooking. The improved varieties showed higher scavenging activity than the local variety both for raw and cooked samples alike. T31 variety raw showed the highest DPPH scavenging activity $(95.56 \%)$ while local raw variety showed the lowest DPPH scavenging

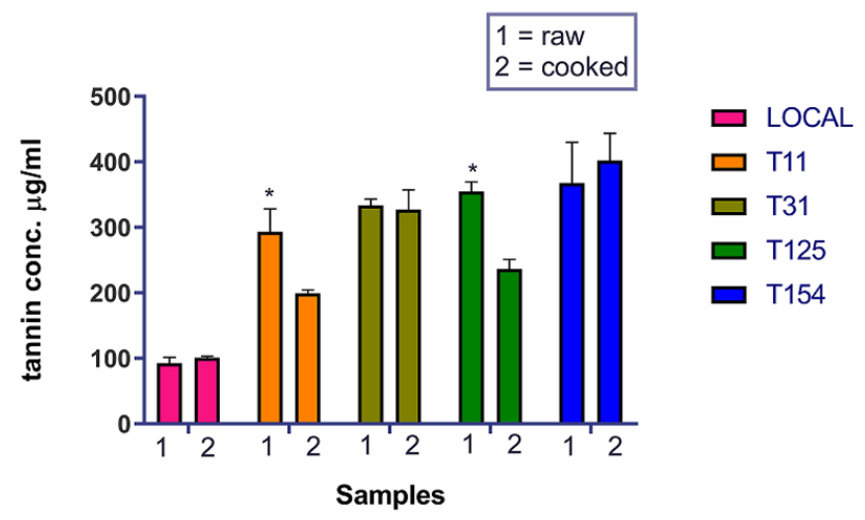

Figure 4. Effect of cooking on tannin content in five different varieties of $\mathrm{P}$. tetragonolobus. LOCAL - indigenous variety, T11, T31, T125, T154 -Tpt-11, Tpt-31, Tpt-125, Tpt-154 (improved variety), 1 - raw, 2 - cooked, * - significant difference.

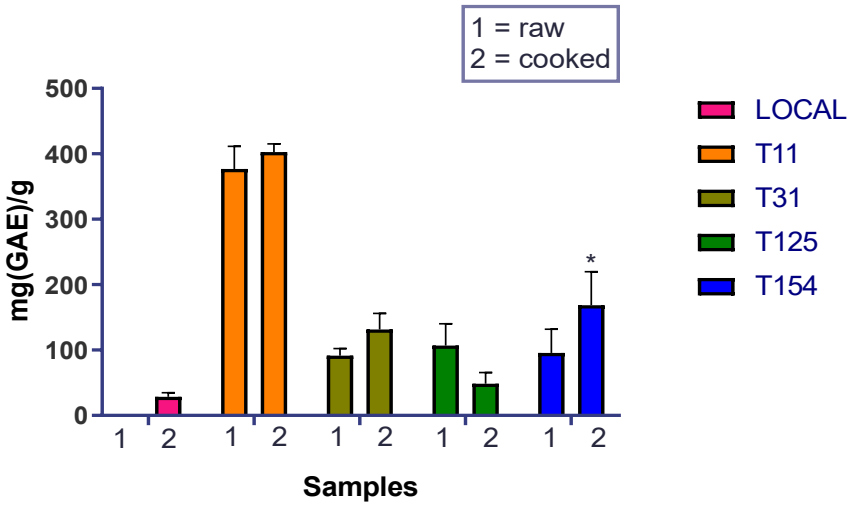

Figure 3. Effect of cooking on phenolic content in five different varieties of P.tetragonolobus. LOCAL - indigenous variety, T11, T31, T125, T154 -Tpt-11, Tpt-31, Tpt-125, Tpt154 (improved variety), 1 - raw, 2 - cooked, * - significant difference.

activity (31.85\%).

\section{Discussion}

A recent study reported that $P$. tetragonolobus is rich in secondary metabolites which give credence to the presence of anti-nutrients in the plant powder analysed (Singh et al., 2019). Antioxidants are vital health factors that play important roles in combatting the effect of reactive nitrogen and oxygen species which could be deleterious to health (Hernández-Hernández et al., 2019). From the DPPH antioxidant activity data obtained, we could say that winged beans varieties studied here could be utilized as a rich source of natural antioxidants due to their high scavenging activity thus conferring on it more functional benefits (Osman, 2007; $\mathrm{Xu}$ et al., 2017). Local raw and Local cooked varieties had lower antioxidant activity as compared to the improved varieties, this might be as a result of a lower quantity of phytochemicals and secondary metabolites like phenolic compounds, carotenes and flavonoids. Also, proteins with a lower amount of sulphur-containing amino acid might result in lower antioxidant activity

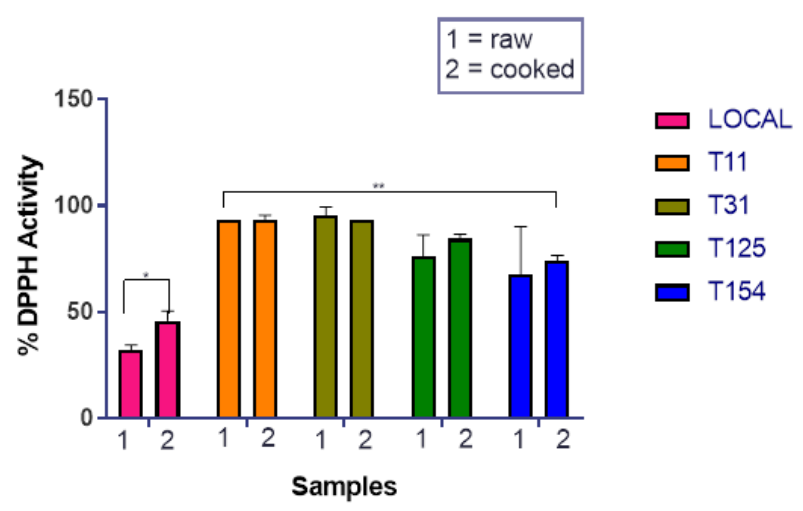

Figure 5. Effect of cooking on \% DPPH in five different varieties of $P$. tetragonolobus. LOCAL - indigenous variety, T11, T31, T125, T154 -Tpt-11, Tpt-31, Tpt-125, Tpt-154 (improved variety), 1 - raw, 2 - cooked, * - significant difference. 
(Kumar and Pandey, 2020).

From the results obtained, the improved variety had more phenolic content than the local variety thus making the improved variety a better source of phenolic compounds than the local. Thus, the high phenolic content in the improved variety might have been responsible for its high DPPH scavenging activity (Othman et al., 2007).

Tannin is a polyphenol and could hinder the body from absorbing iron from some particular foods. Tannins act as secondary antioxidants by chelating metal iron e.g $\mathrm{Fe}$ (II), thereby interfering with a step in the Fenton reaction thereby retarding oxidation. It also has a couple of health benefits as several studies have shown it to have anticancer and antimicrobial activities. Tannins are referred to as antinutrients because they tend to precipitate proteins and inhibit digestive enzymes. They can also decrease the utilization of vitamins and minerals (Koleckar et al., 2008). The high tannin content from the result obtained also suggests a high antioxidant property because of tannin's ability to chelate transition elements and scavenge free radicals that could be detrimental to health. Thereby making it a good natural antioxidant.

The result of phytate from our study showed the same trend with the other antinutrients studied. As the improved variety had a higher phytate concentration as compared to the local variety. Generally, there was a decrease in the phytate concentration of three out of the four improved varieties as a result of cooking. The cooking process might have resulted in a decrease in the phytate antinutrient as various processing methods involving heat application have been reported to decrease antinutrients either through thermal degradation or diffusion (Coffigniez et al., 2019; Kumar and Gautam, 2019).

The effect of cooking on cyanogenic glycoside concentration was not consistent across the five varieties as there was a significant increase observed in some of the varieties while some others experienced a significant decrease after cooking. The local variety had the highest quantity of cyanogenic glycoside as compared to the improved varieties.

\section{Conclusion}

This study was carried out to evaluate the effects of cooking as a processing technique on the antinutrients and antioxidant properties of $P$. tetragonolobus seeds. Data obtained showed that the cooking process reduced the phytate, cyanogenic glycosides and tannin levels in the T11 variety while only the tannin level in T125 variety was significantly reduced. However, the antioxidant activity of $P$. tetragonolobus was not significantly impacted by cooking.

\section{Conflict of interest}

The authors declare no conflict of interest.

\section{References}

Aranda-Olmedo, I. and Rubio, L.A. (2020). Dietary legumes, intestinal microbiota, inflammation and colorectal cancer. Journal of Functional Foods, 64, 103707. https://doi.org/10.1016/j.jff.2019.103707

Bautista-Exposito, S., Penas, E., Silvan, J.M., Frias, J. and Martinez-Villaluenga, C. (2018). pH-controlled fermentation in mild alkaline conditions enhances bioactive compounds and functional features of lentil to ameliorate metabolic disturbances. Food Chemistry, 248, 262-271. https://doi.org/10.1016/ j.foodchem.2017.12.059

Chen, D., Yi, X., Yang, H., Zhou, H., Yu, Y., Tian, Y. and Lu, X. (2015). Genetic diversity evaluation of winged bean (Psophocarpus tetragonolobus (L.) DC.) using inter-simple sequence repeat (ISSR). Genetic Resources and Crop Evolution, 62(6), 823828. https://doi.org/10.1007/s10722-015-0261-3

Coffigniez, F., Briffaz, A., Mestres, C., Akissoe, L., Bohuon, P. and El Maataoui, M. (2019). Impact of soaking process on the microstructure of cowpea seeds in relation to solid losses and water absorption. Food Research International, 119, 268-275. https:// doi.org/10.1016/j.foodres.2019.02.010

Diniyah, N., Badrul Alam, M. and Lee, S.-H. (2020). Antioxidant potential of non-oil seed legumes of Indonesian's ethnobotanical extracts. Arabian Journal of Chemistry, 13(5), 5208-5217. https:// doi.org/10.1016/j.arabjc.2020.02.019

Hernández-Hernández, C., Aguilar, C.N., RodríguezHerrera, R., Flores-Gallegos, A.C., Morlett-Chávez, J., Govea-Salas, M. and Ascacio-Valdés, J.A. (2019). Rambutan (Nephelium lappaceum L.):Nutritional and functional properties. Trends in Food Science and Technology, 85, 201-210. https:// doi.org/10.1016/j.tifs.2019.01.018

Koleckar, V., Kubikova, K., Rehakova, Z., Kuca, K., Jun, D., Jahodar, L. and Opletal, L. (2008). Condensed and hydrolysable tannins as antioxidants influencing the health. Mini Review Medical Chemistry, 8(5), 436-447. https:// doi.org/10.2174/138955708784223486

Kumar, S. and Gautam, S. (2019). A combination process to ensure microbiological safety, extend storage life and reduce anti-nutritional factors in 
legume sprouts. Food Bioscience, 27, 18-29. https:// doi.org/10.1016/j.fbio.2018.11.005

Kumar, S. and Pandey, G. (2020). Biofortification of pulses and legumes to enhance nutrition. Heliyon, 6 (3), e03682. https://doi.org/10.1016/ j.heliyon.2020.e03682

Lepcha, P., Egan, A.N., Doyle, J.J. and Sathyanarayana, N. (2017). A Review on Current Status and Future Prospects of Winged Bean (Psophocarpus tetragonolobus) in Tropical Agriculture. Plant Foods and Human Nutrition, 72(3), 225-235. https:// doi.org/10.1007/s11130-017-0627-0

Makeri, M., Sahri, M.M., Ghazali, H.M., Ahmad, K. and Muhammad, K. (2019). Polymorphism, textural and crystallization properties of winged bean (Psophocarpus tetragonolobus, D.C) oil-based transfatty acids free ternary margarine blends. $L W T$ Food Science and Technology, 100, 158-166. https:// doi.org/10.1016/j.lwt.2018.09.012

Mohanty, C.S., Pradhan, R.C., Singh, V., Singh, N., Pattanayak, R., Prakash, O., Chanotiya, C.S. and Rout, P.K. (2015). Physicochemical analysis of Psophocarpus tetragonolobus (L.) DC seeds with fatty acids and total lipids compositions. Journal of Food Science and Technology, 52(6), 3660-3670. https://doi.org/10.1007/s13197-014-1436-1

Mohanty, C.S., Verma, S., Singh, V., Khan, S., Gaur, P., Gupta, P., Abdul Nazir, M., Dikshit, N., Pattanayak, R., Shukla, A., Niranjan, A., Sahu, N., Behera, S.K. and Rana, S.T. (2013). Characterization of winged bean (Psophocarpus tetragonolobus (L.) DC.) based on molecular, chemical and physiological parameters. American Journal of Molecular Biology, 3, 187-197. https://doi.org/10.4236/ajmb.2013.34025

Mohapatra, D., Patel, A.S., Kar, A., Deshpande, S.S. and Tripathi, M.K. (2019). Effect of different processing conditions on proximate composition, anti-oxidants, anti-nutrients and amino acid profile of grain sorghum. Food Chemistry, 271, 129-135. https:// doi.org/10.1016/j.foodchem.2018.07.196

Osman, A.M. (2007). Effect of Different Processing Methods, on Nutrient Composition, Antinutrional Factors, and in vitro Protein Digestibility of Dolichos Lablab Bean [Lablab purpuresus (L) Sweet]. Pakistan Journal of Nutrition, 6(4), 299-303. https://doi.org/10.3923/pjn.2007.299.303

Othman, A., Ismail, A., Abdul Ghani, N. and Adenan, I. (2007). Antioxidant capacity and phenolic content of cocoa beans. Food Chemistry, 100(4), 1523-1530. https://doi.org/10.1016/j.foodchem.2005.12.021

Owuamanam, C., Ogueke, C., Iwouno, J. and Edom, T. (2014). Use of Seed Sprouting in Modification of
Food Nutrients and Pasting Profile of Tropical Legume Flours. Nigerian Food Journal, 32(1), 117125. https://doi.org/10.1016/S0189-7241(15)30104-1

Singh, M., Dubey, R.K., Koley, T.K., Maurya, A., Singh, P.M. and Singh, B. (2019). Valorization of winged bean (Psophocarpus tetragonolobus (L) DC) by evaluation of its antioxidant activity through chemometric analysis. South African Journal of Botany, 121, 114-120. https://doi.org/10.1016/ j.sajb.2018.10.026

Subuola, F., Widodo, Y. and Kehinde, T. (2012). Processing and Utilization of Legumes in the Tropics. In Eissa, A.A. (Ed.) Trends in Vital Food and Control Engineering. IntechOpen E-Book. https://doi.org/10.5772/36496

Teixeira-Guedes, C.I., Oppolzer, D., Barros, A.I. and Pereira-Wilson, C. (2019). Impact of cooking method on phenolic composition and antioxidant potential of four varieties of Phaseolus vulgaris $\mathrm{L}$. and Glycine max L. LWT - Food Science and Technology, 103, 238-246. https://doi.org/10.1016/ j.lwt.2019.01.010

Xu, D.P., Li, Y., Meng, X., Zhou, T., Zhou, Y., Zheng, J., Zhang, J.-J. and Li, H.B. (2017). Natural Antioxidants in Foods and Medicinal Plants: Extraction, Assessment and Resources. International Journal of Molecular Science, 18(1), 96. https:// doi.org/10.3390/ijms18010096 